\title{
New Anterior Myocardial Infarction by ECG Finding
}

National Cancer Institute

\section{Source}

National Cancer Institute. New Anterior Myocardial Infarction by ECG Finding. NCI

Thesaurus. Code C102732.

An electrocardiographic finding of pathologic Q waves in leads V3 and V4, which is suggestive of myocardial infarction of the anterior wall of the left ventricle and which is new compared to prior ECGs. (CDISC) 